\title{
Effects of leaf-to-fruit ratio on chlorophyll fluorescence parameters of walnut (Juglans regia $\mathrm{L}$.) leaves
}

\author{
C.F. ZHANG, C.D. PAN ${ }^{+}$, and H. CHEN \\ College of Forestry and Horticulture, Xinjiang Agricultural University/Key Laboratory of Forestry Ecology and Industry \\ Technology in Arid Region, Education Department of Xinjiang, No. 311 Nongdadong Rd., Urumqi, 830052, Xinjiang, \\ China
}

\begin{abstract}
In this study, we investigated maximal quantum yield of PSII photochemistry $\left(\mathrm{F}_{\mathrm{v}} / \mathrm{F}_{\mathrm{m}}\right)$, effective quantum yield of PSII photochemistry ( $\left.\Phi_{\mathrm{PSII}}\right)$, and nonphotochemical quenching (NPQ) of walnut (Juglans regia 'Xinxin2') leaves with different leaf-to-fruit ratios (LFRs). The results indicated that the increasing LFR increased the values of $F_{v} / F_{m}$, $\Phi_{P S I I}$, and NPQ in leaves on the girdled shoot with one and two leaves, and decreased the values of $F_{\mathrm{v}} / \mathrm{F}_{\mathrm{m}}$ and $\Phi_{\mathrm{PSII}}$ in leaves on the girdled shoot with five leaves, whereas had no effect on the chlorophyll (Chl) fluorescence in leaves on the girdled shoot with three and four leaves. These results indicate that the effects of LFR on Chl fluorescence depend on a LFR range and show a transitional trend transition, and that excessive fruit load accelerates leaf senescence resulting in the destruction of the reaction center in PSII.
\end{abstract}

Additional key words : defoliation; fruit tree; photochemical efficiency of PSII.

\section{Introduction}

Effects of LFR on vegetative growth, fruit development, biomass productivity, photosynthetic characteristics of leaves have been studied in many fruit varieties, e.g., olive (Olea europaea L.) (Dag et al. 2010, Martín-Vertedor et al. 2011, Naor et al. 2012), European plum (Prunus domestica L.) (Seehuber et al. 2011), apricot (Prunus armeniaca L.) (Roussos et al. 2011), peach (Prunus persica L. Batsch) (Li et al. 2007), and grape (Vitis vinifera L.) (Rossouw et al. 2017). However, carbohydrates and energy, which are used for vegetative growth, fruit development, and biomass productivity are both the products of photosynthesis in source leaves. Thus, effects of LFR on photosynthesis have always been the hot topics.

In fruit trees, LFR is an important factor probably to influence light energy capture and transportation, and photosynthate distribution, and then finally to influence the plant productivity (Zhu et al. 2015). Chl fluorescence is tightly related to photosynthesis and can reflect the actual state of photosynthetic apparatus of leaves under abiotic and biotic stress (Schreiber et al. 1995). Thus, studying the effects of LFR on Chl fluorescence is important to understand the regulatory mechanism of photosynthesis and fundamental plant physiology. Knowledge of the mechanism may also be useful for improving plant productivity.

There are studies indicating that LFR has significant effects on Chl fluorescence. For example, study on peach has shown that the remaining leaves after defoliation have significantly lower net photosynthetic rate $\left(P_{\mathrm{N}}\right)$, maximal fluorescence $\left(\mathrm{F}_{\mathrm{m}}\right)$, and $\mathrm{F}_{\mathrm{v}} / \mathrm{F}_{\mathrm{m}}$ than the leaves initally covered with bags and uncovered at different time (Li et al. 2007). Study on olive indicates that flower thinning decreases $\Phi_{\text {PSII }}$, but increases NPQ in a short term. The reduction in $\Phi_{\text {PSII }}$ might be the main reason for the depression of $P_{\mathrm{N}}$ in the long-term response of $\mathrm{Chl}$ fluorescence to sink source relationship (Zhu et al. 2015).

Received 10 June 2017, accepted 1 January 2018, published as online-first 21 June 2018.

${ }^{+}$Corresponding author; phone: +86 09918763728, email: pancunde@163.com

Abbreviations: Chl - chlorophyll; DAF - days after full bloom of female flowers; $\mathrm{F}_{0}$ - minimal fluorescence yield of the dark-adapted state; $F_{m}$ - maximal fluorescence yield of the dark-adapted state; $F_{m}$ ' - maximal fluorescence yield of the light-adapted state; $F_{s}-$ steadystate fluorescence yield; $\mathrm{F}_{\mathrm{v}} / \mathrm{F}_{\mathrm{m}}$ - maximal quantum yield of PSII photochemistry; LFR - leaf-to-fruit ratio; NPQ - nonphotochemical quenching; $P_{\mathrm{N}}$ - net photosynthetic rate; OTL - LFRs with one and two leaves; TFL - LFRs with three and four leaves; FL - FRs with five leaves; $\Phi_{\text {PSII }}$ - effective quantum yield of PSII photochemistry.

Acknowledgements: The first author thanks to Dr. Pan Cunde for his valuable help in thesis writing and data analysis and Chen Hong for her valuable help in experimental guidance. This study was funded by the National Natural Science Foundation of China (31460210; 31760219), Xinjiang Uygur Autonomous Region University Research Project (major project) (XJEDU20171006) and the Graduate Student Scientific Research and Innovation Program of Xinjiang Uyghur Autonomous Region, China (XJGRI2016-058). 
Therefore, the above-mentioned examples have suggested that a low sink demand results in the decreased activity of PSII reaction centers.

There are also studies indicating that the effects of LFR on $\mathrm{Chl}$ fluorescence are not significant. For example, data from olive leaves which were monitored at pit hardening and fruit ripening shows that crop load has no significant effect on Chl fluorescence parameters (Haouari et al. 2013). Study with citrus shows that increase in minimal fluorescence $\left(\mathrm{F}_{0}\right)$ after defruiting is observed on relatively warm days, however, $F_{v} / F_{m}$ which is measured at midday only presents small and probably transient response to crop load (Syvertsen et al. 2003). Therefore, the above mentioned examples have suggested that the change in a source-sink relation has no significant effect on Chl fluorescence.

\section{Materials and methods}

Experimental site and plants: The experiment was carried out in a walnut orchard, located in southwest of Xinjiang, China $\left(41^{\circ} 11^{\prime} 06.31^{\prime \prime}-41^{\circ} 12^{\prime} 47.74^{\prime \prime} \mathrm{N}, 79^{\circ} 12^{\prime}\right.$ $12.76^{\prime \prime}-79^{\circ} 13^{\prime} 57.87^{\prime \prime} \mathrm{E} ; 1,394 \mathrm{~m}$ a. s. 1.). The climate is a warm temperate continental arid environment with a mean annual temperature of $9.4^{\circ} \mathrm{C}$. It receives an average rainfall of $91.5 \mathrm{~mm}$. Uniform 10-year-old walnut ( $J$. 'Xinxin2') trees were grown at a spacing of $5.0 \times 6.0 \mathrm{~m}$ in east-west rows in anthropogenic-alluvial soil.

girdled shoots with one fruit and one leaf one leaf and two fruits

one leaf and three fruits

girdled shoots with two leaves and one fruit

two leaves and two fruits

two leaves and three fruits

girdled shoots with three leaves and one fruit three leaves and two fruits

three leaves and three fruits

girdled shoots with four leaves and one fruit

four leaves and two fruits

four leaves and three fruits

girdled shoots with five leaves and one fruit

five leaves and two fruits

five leaves and three fruits
The inconsistent information from previous studies has tended to obscure the effect of LFR on Chl fluorescence. Thus, there must be enough studies to demonstrate such an effect. Furthermore we are not quite clear about the effects of LFR on Chl fluorescence of walnut (Juglans regia L.) leaves. Thus, we put forward the hypothesis that: the effect of LFR on Chl fluorescence depends on the variation range of LFR. In this study, the different LFRs of walnut trees were artificially altered using a variety of manipulations, including defoliation, fruit thinning, and girdling. After manipulation, $\mathrm{Chl}$ fluorescence parameters of leaves on girdled shoots with different LFRs were investigated to evaluate the long-term response of $\mathrm{Chl}$ fluorescence to LFR, and to determine their relationship during the growing season. This study will provide a deeper understanding of the effect of LFRs on Chl fluorescence.

Leaf-to-fruit ratio manipulation: After fruit set, 15 LFRs were applied to sun-exposed and girdled shoots with fully expanded leaves and developing fruit by removing fruit or leaves on the southern side of homogenous trees. LFRs used in this study reflected the bearing habit found in walnut trees under natural conditions and was defined as the ratio of a number of leaves to the number of fruits. The measurement of $\mathrm{Chl}$ fluorescence parameters was performed with six trees; fifteen girdled shoots of each tree were subjected to all of the following 15 LFR treatments (Fig. 1):
Girdling was applied at the shoot base after defoliation or defruiting in order to prevent the exchange of carbohydrates between treated shoots and other parts of the tree. The girdles were preserved for the entire growing season by discarding any scar tissue at $15-\mathrm{d}$ intervals. Immature leaves and the apical and auxiliary buds were removed from the treated shoots to ensure that the assimilates mainly flowed to the fruits.

Chl fluorescence parameters: During the 2016 growing seasons, Chl fluorescence parameters were measured once
1L:1F (Fig. 1A)
1L:2F (Fig. 1B)
1L:3F (Fig. 1C)
2L:1F (Fig. 1D)
2L:2F (Fig. $1 E$ )
L:3F (Fig. $1 F$ )
(Fig. $1 G$ )
$3 \mathrm{~L} \cdot 3 \mathrm{~F}$ (Fig. $1 \mathrm{I})$
4L:1F (Fig. 1J)
4L:2F (Fig. $1 K$ )
4L:3F (Fig. $1 L$ )
$5 \mathrm{~L}: 1 \mathrm{~F}$ (Fig. $1 M$ )
5L:2F (Fig. $1 N$ )
5L:3F (Fig. 1O)

a day (11:00-14:00), on five cloudless days at 7, 22, 52, 82, and $107 \mathrm{~d}$ after initiating LFR manipulation (i.e., 30, $45,75,105$, and $130 \mathrm{~d}$ after full bloom of female flowers). Two fully developed leaves per girdled shoot close to the developing fruit were selected for the Chl fluorescence measurement, which was assessed using a fluorescence monitoring system (FMS-2, Hansatech, England). The selected leaves were placed in the dark for $20 \mathrm{~min}$, and then a low-intensity $\left[<5 \mu\right.$ mol(photon) $\left.\mathrm{m}^{-2} \mathrm{~s}^{-1}\right]$ redmeasuring light was applied first to obtain minimum fluorescence, $F_{0}$. Then, maximum fluorescence, $F_{m}$, was 

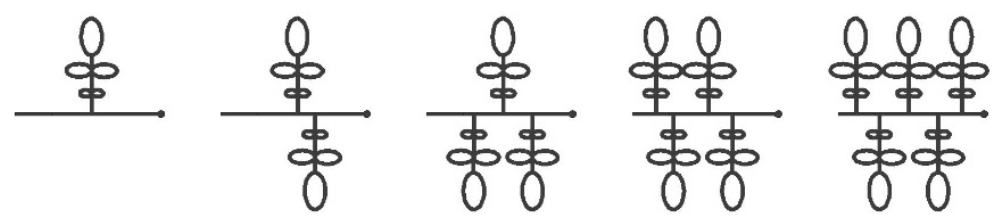

A. 1L:1F

$D \cdot 2 \mathrm{~L}: 1 \mathrm{~F}$
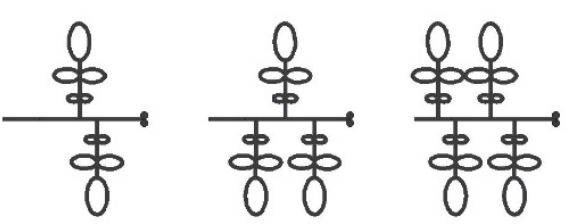

$K \cdot 4 \mathrm{~L}: 2 \mathrm{~F}$

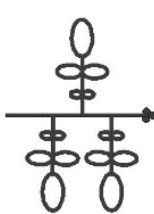

1. 3L:3F

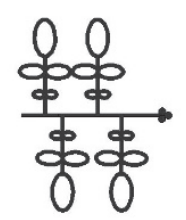

L. 4L:3F

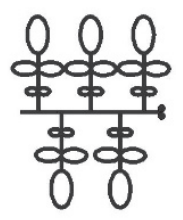

$N \cdot 5 \mathrm{~L}: 2 \mathrm{~F}$

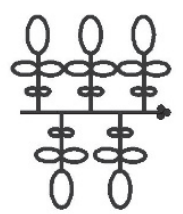

O. $5 \mathrm{~L}: 3 \mathrm{~F}$

Fig. 1. Different leaf-to-fruit ratio manipulations on the girdled shoots of walnut.

obtained under a saturating light $\left[<5 \mu \mathrm{mol}\right.$ (photon) $\left.\mathrm{m}^{-2} \mathrm{~s}^{-1}\right]$ red-measuring light was applied first to obtain minimum fluorescence, $\mathrm{F}_{0}$. Then, maximum fluorescence, $\mathrm{F}_{\mathrm{m}}$, was obtained under a saturating light pulse $(0.8 \mathrm{~s})$ of 6,000 $\mu \mathrm{mol}\left(\right.$ photon) $\mathrm{m}^{-2} \mathrm{~s}^{-1}$. The same leaves after dark measurement, were first exposed to normal light for $30 \mathrm{~min}$ and then were illuminated by actinic light $[700 \mu \mathrm{mol}$ (photon) $\mathrm{m}^{-2} \mathrm{~s}^{-1}$ ] for $150 \mathrm{~s}$ to determine the steady-state fluorescence $\left(\mathrm{F}_{\mathrm{s}}\right)$, and then maximum fluorescence in the lightadapted state $\left(\mathrm{F}_{\mathrm{m}}\right.$ ') could be measured by applying saturating white light pulse $(0.8 \mathrm{~s})$ of $6,000 \mu \mathrm{mol}$ (photon) $\mathrm{m}^{-2} \mathrm{~s}^{-1} . \mathrm{F}_{\mathrm{v}} / \mathrm{F}_{\mathrm{m}}$ and $\Phi_{\mathrm{PS} \text { II }}$ were calculated by a $F M S$ - 2 instrument. Nonphotochemical quenching, NPQ, was calculated as follows:

$$
\mathrm{NPQ}=\left(\mathrm{Fm}_{\mathrm{m}}-\mathrm{Fm}^{\prime}\right)^{\prime} / \mathrm{Fm}^{\prime}
$$

Statistical analysis: Data were statistically analyzed using SPSS ver. 22.0 statistical software. Firstly, repeatedmeasures analysis was used to examine the effects of LFR, growth stage, and their interaction on the profiles of $\mathrm{Chl}$ fluorescence parameters. Then profile analysis was used to determine whether the Chl fluorescence parameters differed significantly between two different LFRs. $\mu_{1}{ }^{\prime}=$ $\left(\mu_{11}, \mu_{12}, \mu_{13}, \mu_{14}, \mu_{15}\right)$ and $\mu_{2}{ }^{\prime}=\left(\mu_{21}, \mu_{22}, \mu_{23}, \mu_{24}, \mu_{25}\right)$, respectively, represented mean vectors of two different LFR crossed five growth stages. Each profile was the average

\section{Results}

According to the result of repeated-measures analysis (Table 1), the effects of LFR, growth stage, and their interaction on the Chl fluorescence parameters were statistically significant. The values of three Chl fluores values of one $\mathrm{Chl}$ fluorescence parameter across five growth stages for the same treatment from six replicated samples. Profile analysis addressed two questions.

(1) Whether the two profiles were parallel or not?

$$
\text { Ho1: } \mu 1 \mathrm{i}-\mu 1, \mathrm{i}-1, \mathrm{i}=2,3,4,5
$$

The hypothesis $\mathrm{H}_{01}$ was tested by the result of multivariate tests. $P<0.05$ indicated hypothesis $\mathrm{H}_{01}$ was rejected, that was, there was significant difference between the two LFRs of test takers. $P>0.05$ indicated hypothesis $\mathrm{H}_{01}$ was accepted, and then the hypothesis $\mathrm{H}_{02}$ (coincidence profile test) was tested.

(2) Whether the two profiles were coincident or not?

$$
\text { H02: } \mu 1 \mathrm{i}-\mu 2 \mathrm{i}, \mathrm{i}=2,3,4,5
$$

The hypothesis $\mathrm{H}_{02}$ was tested by the result of tests of between subject effects. $P<0.05$ indicated hypothesis $\mathrm{H}_{02}$ was rejected, that was, there was significant difference between the two LFRs of test takers. $P>0.05$ indicated hypothesis $\mathrm{H}_{02}$ was accepted and there was no significant difference between the two LFRs of test takers (Kruskal 1964).

General linear regression analysis was applied to determine the relationship between LFR and Chl fluorescence parameters.

cence parameters varied greatly with different LFR and growth stages. And the change trend of the values with growth stages was affected by LFR. 
Table 1. Repeated-measures analysis of $\mathrm{Chl}$ fluorescence parameters profiles. $F_{\mathrm{v}} / \mathrm{F}_{\mathrm{m}}$ - maximal quantum yield of PSII photochemistry, $\Phi_{\text {PSII }}$ - photochemical efficiency of PSII photochemistry, NPQ - nonphotochemical qunching; F - the statistic value of analysis of variance; $P$ - the probability values under the corresponding $F$ values.

\begin{tabular}{lllll}
\hline & & $\mathrm{F}_{\mathrm{v}} / \mathrm{F}_{\mathrm{m}}$ & $\Phi_{\mathrm{PSII}}$ & $\mathrm{NPQ}$ \\
\hline Growth stage (S) & $F$ & $2,095.024$ & 762.824 & $1,437.453$ \\
& $P$ & 0.000 & 0.000 & 0.000 \\
Treatments with different & $F$ & 511.292 & 174.594 & 247.589 \\
leaf-to-fruit ratios (T) & $P$ & 0.000 & 0.000 & 0.000 \\
$\mathrm{~T} \times \mathrm{S}$ & $F$ & 55.694 & 4.119 & 19.101 \\
& $P$ & 0.000 & 0.000 & 0.000 \\
\hline
\end{tabular}
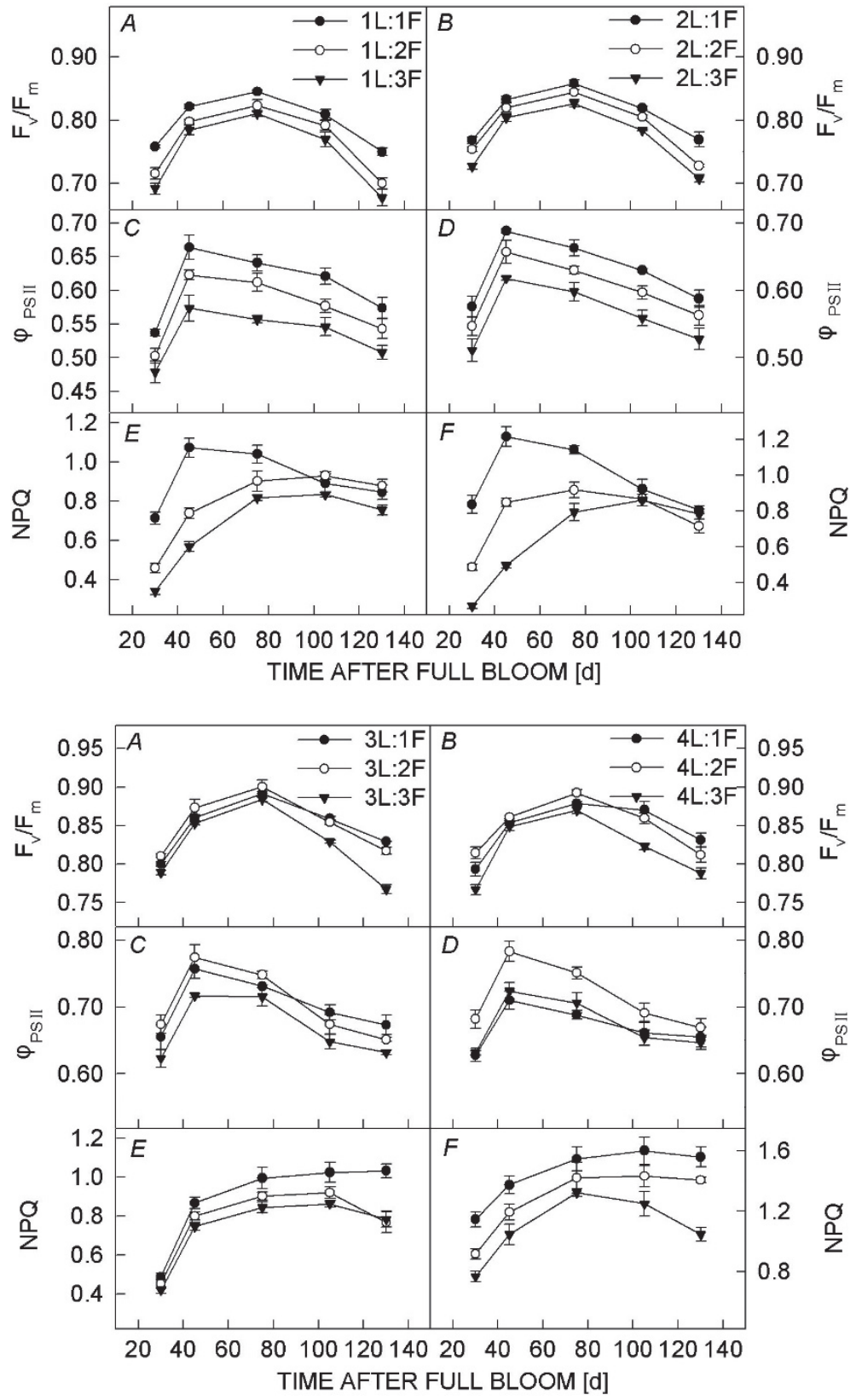

LFRs with one and two leaves (OTL): In the girdled shoots with one and two leaves (Fig. 2), $\mathrm{F}_{\mathrm{v}} / \mathrm{F}_{\mathrm{m}}, \Phi_{\text {PSII }}$, and NPQ decreased significantly with increasing fruit load. Integrated over the growing season, LFRs with one fruit (1L:1F and $2 \mathrm{~L}: 1 \mathrm{~F})$ had larger values of $\mathrm{F}_{\mathrm{v}} / \mathrm{F}_{\mathrm{m}}, \Phi_{\mathrm{PSII}}$, and NPQ than LFRs with three fruit (1L:3F and $2 \mathrm{~L}: 3 \mathrm{~F})$, with $1 \mathrm{~L}: 2 \mathrm{~F}$ and $2 \mathrm{~L}: 2 \mathrm{~F}$ showing intermediate values. On the basis of profile analysis, any two LFRs for $F_{v} / F_{m}$ and $\Phi_{\text {PSII }}$ showed up as a significantly distinct profile since they were not coincident, although $\mathrm{F}_{\mathrm{v}} / \mathrm{F}_{\mathrm{m}}$ and $\Phi_{\text {PSII }}$ varied curvilinearly across the growing season in all LFRs. However, LFR made some difference in the patterns of NPQ.

Fig. 2. Changes in Chl fluorescence parameters in response to leaf-to-fruit ratios (LFRs) with one and two leaves. Data are presented as means \pm SD $(n=6) .(A, B)$ the maximal quantum yield of PSII photochemistry $\left(\mathrm{F}_{\mathrm{v}} / \mathrm{F}_{\mathrm{m}}\right)$ of LFRs with one leaf and two leaves, respectively; $(C, D)$ effective quantum yield of PSII photochemistry (ФPSII) of LFRs with one leaf and two leaves, respectively; $(E, F)$ nonphotochemical quenching (NPQ) of LFRs with one leaf and two leaves, respectively.

Fig. 3. Changes in Chl fluorescence parameters in response to leaf-to-fruit ratios (LFRs) with three and four leaves. Data are presented as means \pm SD $(n=6) .(A, B)$ the maximal quantum yield of PSII photochemistry $\left(\mathrm{F}_{\mathrm{v}} / \mathrm{F}_{\mathrm{m}}\right)$ of LFRs with three leaves and four leaves, respectively; $(C, D)$ effective quantum yield of PSII photochemistry ( $\Phi_{\text {PSII }}$ ) of LFRs with three leaves and four leaves, respectively; $(E, F)$ nonphotochemical quenching (NPQ) of LFRs with three leaves and four leaves, respectively. 
LFRs with three and four leaves (TFL): In the girdled shoots with three and four leaves (Fig. 3), NPQ decreased significantly with increasing fruit load. LFRs with one fruit $(3 \mathrm{~L}: 1 \mathrm{~F}$ and $4 \mathrm{~L}: 1 \mathrm{~F})$ showed the highest annual mean NPQ values. However, a similar response in LFRs in $F_{v} / F_{m}$ and $\Phi_{\text {PSII }}$ was observed for all the LFRs. Results of profile analysis showed that there were no significant differences in $F_{\mathrm{v}} / \mathrm{F}_{\mathrm{m}}$ and $\Phi_{\text {PSII }}$ between any two LFRs, with the exception of $3 \mathrm{~L}: 3 \mathrm{~F}$ and $4 \mathrm{~L}: 2 \mathrm{~F}$.

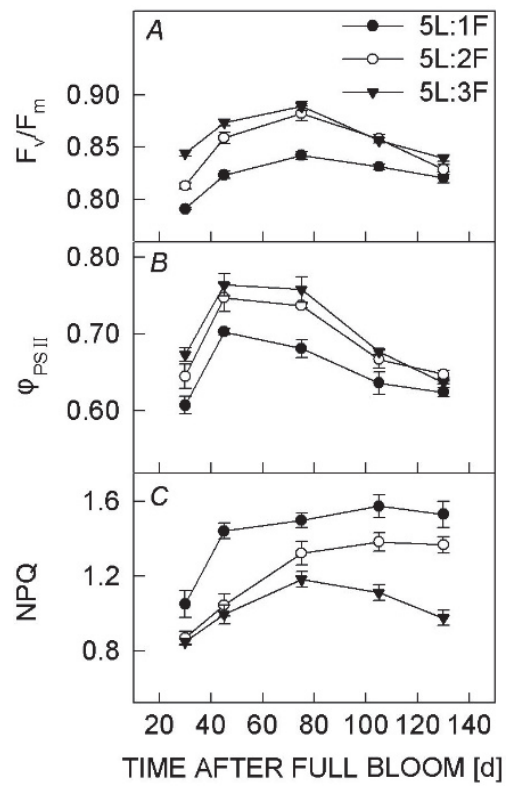

Fig. 4. Changes in Chl fluorescence parameters in response to leaf-to-fruit ratios (LFRs) with five leaves. Data are presented as means $\pm \mathrm{SD}(n=6)$. $(A)$ The maximal quantum yield of PSII photochemistry $\left(\mathrm{F}_{\mathrm{v}} / \mathrm{F}_{\mathrm{m}}\right)$ of LFRs with five leaves; $(B)$ effective quantum yield of PSII photochemistry (ФPSII) of LFRs with five leaves; $(C)$ nonphotochemical quenching (NPQ) of LFRs with five leaves.

LFRs with five leaves (FL): In the girdled shoots with five leaves (Fig. 4), the values of $F_{v} / F_{m}$ and $\Phi_{\text {PSII }}$ decreased

\section{Discussion}

The induced Chl fluorescence as a kinetic parameter plays an important role in research of photosynthetic physiological conditions and studying the mechanism of photosynthesis due to its celerity and undamage to plants (Hazrati et al. 2016, Mouradi et al. 2016). In this study, LFR was manipulated in walnut trees in the absence of perturbation of other functional sinks such as roots and branches. To study the effect of LFR on Chl fluorescence, ninety girdled shoots with fifteen LFR were implemented during the entire growing season, and three Chl fluorescence parameters $\left(\mathrm{F}_{\mathrm{v}} / \mathrm{F}_{\mathrm{m}}, \Phi_{\mathrm{PSII}}\right.$, and NPQ) were analyzed.

$\mathrm{F}_{\mathrm{v}} / \mathrm{F}_{\mathrm{m}}$ as the maximum photochemical quantum yield of PSII is obtained under the conditions of all photosystem significantly with increasing LFR. Integrated over the growing season, $5 \mathrm{~L}: 3 \mathrm{~F}$ had larger values of $\mathrm{F}_{\mathrm{v}} / \mathrm{F}_{\mathrm{m}}$ and $\Phi_{\text {PSII }}$ than $5 \mathrm{~L}: 1 \mathrm{~F}$, with $5 \mathrm{~L}: 2 \mathrm{~F}$ showing intermediate values (Fig. 4A,B). NPQ decreased significantly with the increasing fruit load. 5L:3F showed the lowest annual mean NPQ value, which was respectively 14.6 and $27.9 \%$ lower than that for $5 \mathrm{~L}: 2 \mathrm{~F}$ and $5 \mathrm{~L}: 1 \mathrm{~F}$.

Table 2. The relationship between leaf to fruit ratio $(\mathrm{x})$ and chlorophyll fluorescence parameters (y). The relationships are indicated by the linear regression equations of the form $\mathrm{y}=\mathrm{mx}$ $+\mathrm{c}$, where $\mathrm{x}$ and $\mathrm{y}$ are independent and dependent variables, respectively, and $\mathrm{m}$ and $\mathrm{c}$ are slope and intercept, respectively. $R^{2}$ - correlation coefficient for each relationship. Levels of statistical significance are: $* P<0.05, * * P<0.01$. "-" indicates no correlation between variables. $\mathrm{F}_{\mathrm{v}} / \mathrm{F}_{\mathrm{m}}-$ maximal quantum yield of PSII photochemstry; $\Phi_{\text {PSII }}$ - photochemical efficiency of PSII photochemstry; NPQ - nonphotochemical quenching; OTL leaf-to-fruit ratio (LFR) with one and two leaves; TFL - LFR with three and four leaves; FL - LFR with five leaves.

\begin{tabular}{llll}
\hline LFR & Parameter & Linear regression equation & $R^{2}$ \\
\hline OTL & $F_{\mathrm{v}} / F_{\mathrm{m}}$ & $\mathrm{y}=0.035 \mathrm{x}+0.748 \mathrm{y}$ & $0.831^{* *}$ \\
& $\Phi_{\text {PSII }}$ & $\mathrm{y}=0.052 \mathrm{x}+0.536 \mathrm{y}$ & $0.814^{* *}$ \\
& NPQ & $\mathrm{y}=0.189 \mathrm{x}+0.620 \mathrm{y}$ & $0.697^{*}$ \\
TFL & $F_{\mathrm{v}} / \mathrm{F}_{\mathrm{m}}$ & - & - \\
& $\Phi_{\text {PSII }}$ & - & - \\
& NPQ & - & - \\
FL & $F_{\mathrm{v}} / \mathrm{F}_{\mathrm{m}}$ & $\mathrm{y}=-0.120 \mathrm{x}+0.879 \mathrm{y}$ & $0.980^{* *}$ \\
& $\Phi_{\text {PSII }}$ & $\mathrm{y}=-0.015 \mathrm{x}+0.727 \mathrm{y}$ & $0.997^{* *}$ \\
& NPQ & - & - \\
\hline
\end{tabular}

Correlation between LFR and $\mathrm{Chl}$ fluorescence parameters: When relationships of the data of $F_{\mathrm{v}} / F_{\mathrm{m}}, \Phi_{\text {PSII }}$, and NPQ with the data of LFR were investigated using mean values of the data, it was found that OTL were positively correlated with $\mathrm{F}_{\mathrm{v}} / \mathrm{F}_{\mathrm{m}}, \Phi_{\mathrm{PSII}}$, and NPQ, whereas the FL showed negatively significant correlations with $\mathrm{F}_{\mathrm{v}} / \mathrm{F}_{\mathrm{m}}$ and $\Phi_{\text {PSII }}$. TFL showed no correlation with all the Chl fluorescence parameters (Table 2).

reaction centers being in an open state, and it reflects the intrinsic efficiency of energy conversion in the PSII reaction center (Oxborough and Baker 1997, Gorbe and Calatayud 2012). $\Phi_{\text {PSII }}$ reflects PSII activities and evaluates the transfer rate of electrons transporting from PSII to PSI (Krall and Edward 1992). Nonphotochemical quenching (NPQ) is a photoprotective process that removes excess excitation energy in the form of heat dissipation, which is closely related to xanthophyll cycling and prevents the likelihood of formation of damaging reactive oxygen species (ROS). Production of large amounts of ROS is inevitable during photosynthesis process, e.g., singlet-excited oxygen and hydroxyl radical, which can oxidize surrounding bimolecular. If the 
nonradiative energy dissipation of the xanthophyll cycle cannot completely dissipate excess light energy, which will form ROS and cause damage to the photosynthetic mechanism (Apel and Hirt 2004, Demmig-Adams 1990, Pinnola et al. 2013). Under optimal circumstances, the Chl in plant leaves dissipate absorbed light by photosynthetic electron transport, Chl fluorescence emission, and heat dissipation. There is a reciprocal relationship among these three processes. Changes in photosynthesis and heat dissipation causes the corresponding changes in fluorescence (Zheng and Shangguan 2006).

In the girdled shoots with one and two leaves, LFRs were positively correlated with $\mathrm{F}_{\mathrm{v}} / \mathrm{F}_{\mathrm{m}}, \Phi_{\mathrm{PSII}}$, and NPQ (Table 2). The decrease in values of $\mathrm{F}_{\mathrm{v}} / \mathrm{F}_{\mathrm{m}}, \Phi_{\mathrm{PSII}}$, and NPQ with increasing fruit load indicated that extremely low LFRs (1L:2F, 1L:3F, 2L:2F, and $2 \mathrm{~L}: 3 \mathrm{~F}$ ) reduced the efficiency of energy conversion, actual photosynthetic efficiency, and heat dissipation. On the basis of our results, we deduced that there were less absorbed light allocated to these three approaches. It means that there was less light energy captured by $\mathrm{Chl}$ in the leaf. Compared to LFRs with more leaves, under the same light conditions, the lower values of $F_{\mathrm{v}} / F_{\mathrm{m}}, \Phi_{\text {PSII }}$, and NPQ observed at OTL indicated that leaves in OTL had a poor ability to capture light energy. It is probably caused by abnormal photosynthetic function due to the underdeveloped leaves. The photosynthates produced by plant leaves are initially utilized to meet leaf own physiological needs, and then the surplus photosynthates is exported to other sinks ( $\mathrm{Lv}$ and Zhang 2000). However, serious scarcity of photosynthates caused by precious extremely low LFR seriously affected the development of leaves and their photosynthetic apparatus (Fang et al. 2001), which might explain why most $\mathrm{F}_{\mathrm{v}} / \mathrm{F}_{\mathrm{m}}$ values were below 0.8 . The serious scarcity of photosynthates would further impede the development of photosynthetic apparatus. In addition, the effect of girdling on the leaf development should not be ignored. Girdling blocks the flow of nutrients transported from roots through phloem to leaves, which is not conducive to the development of leaves (Fang et al. 2001). It has been proven that girdling reduced $\mathrm{F}_{\mathrm{v}} / \mathrm{F}_{\mathrm{m}}$ (Nebauer et al. 2011) and extremely low LFR resulted in a decrease in photosynthesis (Fang et al. 2001). Thus, we deduced that in OTL, the depressing effect of girdling on Chl fluorescence was stronger than the positive effect of the decrease in LFR on Chl fluorescence, which led to the positive correlation between LFR and Chl fluorescence.

In the girdled shoots with five leaves, LFRs showed negatively significant correlations with $\mathrm{F}_{\mathrm{v}} / \mathrm{F}_{\mathrm{m}}$ and $\Phi_{\mathrm{PSII}}$, which is consistent with the reports for other plants (Li et al. 2007, Zhu et al. 2015). The greater values of $\Phi_{\text {PSII }}$ indicated that photosynthetic apparatus had a better ability to convert light energy. In the present study, the leaves of the highest LFR (5L:1F) showed a loss of $\Phi_{\text {PSII }}($ Fig. $3 A$ ), which implied that if supply exceeded demand, then the light-use efficiency for photosynthesis must decrease (van Rooijen et al. 2015). The increase in $\mathrm{F}_{\mathrm{v}} / \mathrm{F}_{\mathrm{m}}$ and decrease in
NPQ with the increasing fruit load indicated that fruit showed a strong demand for photosynthate (Fischer et al. 2013), which improved the solar energy conversion efficiency of PSII and reduced the thermal energy dissipation. The similar results were observed in peach (Duan et al. 2008) and cherry (Layne and Flore 1993). On the basis of our results, we deduced that under the same light conditions, high fruit load consumes a large portion of absorbed light energy by photosynthetic electron transport. Thus, a relatively little portion of absorbed light energy is consumed by heat dissipation. In the present study, the lowest value of $F_{\mathrm{v}} / \mathrm{F}_{\mathrm{m}}$ and $\Phi_{\text {PSII }}$ and the highest value of NPQ were observed in 5L:1F (Fig. 4). Previous studies suggest that leaf photosynthesis is affected by the light availability and the demand for photosynthates from the other sink (Adams III et al. 2015). Removal of fruit leads to the accumulation of carbohydrate in the leaves and the downregulation of photosynthesis, which is accompanied by significantly greater decreases in $\mathrm{F}_{\mathrm{v}} / \mathrm{F}_{\mathrm{m}}$ and $\Phi_{\mathrm{PSII}}$ and increase in NPQ (Duan et al. 2008, Cheng et al. 2009). High LFR also contributed to the accumulation of carbohydrates when the plant's other sinks fail to utilize the photosynthate by phloem girdling. Thus, we deduced that in FL, the positive effect of the decrease in LFR on Chl fluorescence was stronger than the depressing effect of girdling on Chl fluorescence, which led to the negative correlation between LFR and $C h$ l fluorescence $\left(F_{\mathrm{v}} / \mathrm{F}_{\mathrm{m}}\right.$ and $\left.\Phi_{\mathrm{PSII}}\right)$.

In the girdled shoots with three and four leaves, LFRs showed no correlation with all the Chl fluorescence parameters. In the present study, there were no differences in $\mathrm{F}_{\mathrm{v}} / \mathrm{F}_{\mathrm{m}}$ and $\Phi_{\mathrm{PSII}}$ between any two LFRs, with the exception of $3 \mathrm{~L}: 3 \mathrm{~F}$ and $4 \mathrm{~L}: 2 \mathrm{~F}$, which indicated the leaf development and carbohydrate accumulation in leaves on the shoot with three and four leaves were not affected by girdling and LFR, in comparison to OTL and FL. Stable value for $\Phi_{\text {PSII }}$ is due to the balance between supply-side (the processes of formatting excited states of Chl a in PSII) and demand-side (the processes of dissipating excited states of Chl a) (Genty et al. 1989). Thus, we deduced that in TFL, the positive effect of the decrease in LFR on Chl fluorescence might be cancelled out by the depressing effect of girdling on Chl fluorescence. When supply-side processes in source and demand-side processes in sink reach a balanced state, LFR has no significant effect on Chl fluorescence. However, LFRs with three fruit showed the lowest values of $F_{\mathrm{v}} / \mathrm{F}_{\mathrm{m}}, \Phi_{\mathrm{PSII}}$, and NPQ with the exception of NPQ in $4 \mathrm{~L}: 3 \mathrm{~F}$. It is probably the combination of high fruit load, relatively few leaves, and girdling affects the leaf development, and further impedes the development of photosynthetic apparatus. On the basis of our results, we deduced that TFL could be considered as a transient state from OTL to FL, and that LFRs has no effect on Chl fluorescence.

In the present study, it was interesting to note that the seasonal patterns of every $\mathrm{Chl}$ fluorescence parameter in all LFRs were similar, and these general patterns seemed to be independent on the change in LFR. It was probably 
due to the changes in environmental conditions. The results from citrus suggested changes in $P_{\mathrm{N}}$ of the treatments with different LFR depended on the change in the environment conditions, which is tightly related to the leaf temperature (Nebauer et al. 2011). In the present study, the relationship between the Chl fluorescence and environment conditions remains for further study. In addition, it was also interesting to note that at 105-130 d after full bloom, a reduction in three Chl fluorescence parameters $\left(\mathrm{F}_{\mathrm{v}} / \mathrm{F}_{\mathrm{m}}, \Phi_{\mathrm{PSII}}\right.$, and NPQ) were observed for all the LFRs with three fruit. It was probably because excessive load accelerated leaf senescence resulting in the destruction of the reaction center in PSII. It has been reported that the inhibition of leaf photosynthesis by the high availability of photosynthetic products in the absence of fruit depends on the growth stage (Nii 1993, Syvertsen et al. 2003).

\section{References}

Adams W.W.III., Muller O., Cohu C.M. et al.: Photosystem II efficiency and non-photochemical fluorescence quenching in the context of source-sink balance. - In: Demming-Adams B., Garab G., Adams W.W.III., Govindjee (ed.): Non-Photochemical Quenching and Energy Dissipation in Plants, Algae and Cyanobacteria. Advances in Photosynthesis and Respiration, Vol. 40. Pp. 503-529. Springer, Dordrecht 2014.

Apel K., Hirt H.: Reactive oxygen species: metabolism, oxidative stress, and signal transduction. - Annu. Rev. Plant. Biol. 55: 373-399, 2004.

Cheng J., Fan P., Liang Z. et al.: Accumulation of end products in source leaves affects photosynthetic rate in peach via alteration of stomatal conductance and photosynthetic efficiency. - J. Am. Soc. Hortic. Sci. 134: 667-676, 2009.

Dag A., Bustan A., Avni A. et al.: Timing of fruit removal affects concurrent vegetative growth and subsequent return bloom and yield in olive (Olea europaea L.). - Sci. Hortic.-Amsterdam 123: 469-472, 2010.

Demmig-Adams B.: Carotenoids and photoprotection in plants: A role for the xanthophyll zeaxanthin. - BBA-Bioenergetics 1020: 1-24, 1990.

Duan W., Fan P.G., Wang L.J. et al.: Photosynthetic response to low sink demand after fruit removal in relation to photoinhibition and photoprotection in peach trees. - Tree Physiol. 28: 123-132, 2008.

Fang J.B., Zheng F., Chen J.Y. et al.: Effects of source-sink relationship on the photosynthetic intensity of kiwifruit leaves. - In: Proceedings of the $9^{\text {th }}$ Annual Seminar Chinese Horticultural Society. Pp. 75-80. China Press of Science and Technology, Beijing 2001.

Fischer G., Almanza-Merchán P.J., Ramírez F.: Source-sink relationships in fruit species. A review. - Rev. Colomb. Cienc. Hortic. 6: 238-253, 2013.

Genty B., Briantais Y.M., Baker N.: The relationship between the quantum yield of photosynthetic electron transport and quenching of chlorophyll fluorescence. - Biochim. Biophys. Acta 990: 87-92, 1989

Gorbe E., Calatayud A.: Applications of chlorophyll fluorescence imaging technique in horticultural research: a review. - Sci. Hortic.-Amsterdam 138: 24-35,2012.

Haouari A., van Lebeke M.C.., Steppe K. et al.: Fruit thinning
Conclusion: The Chl fluorescence characteristics of leaves at different LFRs showed in this study indicated that the effects of LFR on Chl fluorescence depended on LFR range and showed a transitional trend transition. The positive correlation between LFR (with one and two leaves) and Chl fluorescence is a consequence of the inhibition of leaf development caused by girdling, and the negative correlation between LFR (with five leaves) and $\mathrm{Chl}$ fluorescence $\left(\mathrm{F}_{\mathrm{v}} / \mathrm{F}_{\mathrm{m}}\right.$ and $\left.\Phi_{\mathrm{PSII}}\right)$ is due to a large portion of absorbed light energy consumed by photosynthetic electron transport caused by high fruit load, whereas the LFR has no significant effects on Chl fluorescence when there is a balance supply and demand of photosynthates between source leaf and sink fruit (LFR with three and four leaves). Additionally, excessive fruit load accelerates leaf senescence resulting in the destruction of the reaction center in PSII.

affects photosynthetic activity, carbohydrate levels, and shoot and fruit development of olive trees grown under semiarid conditions - Funct. Plant. Biol. 40: 1179-1186, 2013.

Hazrati S., Tahmasebi-Sarvestani Z., Modarres-Sanavy S.A.M. et al.: Effects of water stress and light intensity on chlorophyll fluorescence parameters and pigments of Aloe vera L. - Plant Physiol. Bioch. 106: 141-148, 2016.

Krall J.P., Edward G.E.: Relationship between photosystem II activity and $\mathrm{CO}_{2}$ fixation in leaves. - Physiol. Plantarum 86:180-187, 1992.

Kruskal J.B.: Multidimensional scaling by optimizing goodness of fit to a non-metric hypothesis. - Psychometrika 29: 1-27, 1964.

Layne D.R., Flore J.A.: Physiological responses of Prunus cerasus to whole-plant source manipulation. Leaf gas exchange, chlorophyll fluorescence, water relations and carbohydrate concentrations. - Physiol. Plantarum 88: 44-51, 1993.

Li W.D., Duan W., Fan P.G. et al.: Photosynthesis in response to sink-source activity and in relation to end products and activities of metabolic enzymes in peach trees. - Tree Physiol. 27: 1307-1318, 2007.

Lv Y.M., Zhang D.P.: Accumulation of sugars in developing fruit. - Plant Physiol. Co. 36: 258-265, 2000.

Martín-Vertedor A.I., Perez Rodríguez J.M., Prieto Losada H. et al.: Interactive responses to water deceits and crop load in olive (Olea europea L. cv Morisca). II: water use, fruit and oil yield. - Agr. Water Manage. 98: 950-958, 2011.

Mouradi M., Bouizgaren A., Farissi M. et al.: Seed osmopriming improves plant growth, nodulation, chlorophyll fluorescence and nutrient uptake in alfalfa (Medicago sativa L.) - rhizobia symbiosis under drought stress. - Sci. Hortic.-Amsterdam 213: 232-242, 2016

Naor A., Schneider D., Ben-Gal A. et al.: The effects of crop load and irrigation rate in the oil accumulation stage on oil yield and water relations of 'Koroneiki' olives. - Irrigation Sci. 31: 781791, 2012.

Nebauer S.G., Renau-Morata B., Guardiola J.L. et al.: Photosynthesis down-regulation precedes carbohydrate accumulation under sink limitation in Citrus. - Tree Physiol. 31: 169-177, 2011.

Nii N.: Fruiting effects on leaf characteristics, photosynthesis, 
and root growth in peach trees. - J. Jpn. Soc. Hortic. Sci. 62: 519-526, 1993.

Oxborough K., Baker N.R.: Resolving chlorophyll $a$ fluorescence images of photosynthetic efficiency into photochemical and non-photochemical components-calculation of $\mathrm{qP}$ and $\mathrm{F}_{\mathrm{v}}$ '/Fm' without measuring $\mathrm{F}_{0}$ '. - Photosynth. Res. 54: 135-142, 1997.

Pinnola A., Dall'Osto L., Gerotto C. et al.: Zeaxanthin binds to light-harvesting complex stress-related protein to enhance nonphotochemical quenching in Physcomitrella patens. - Plant Cell. 25: 3519-3534, 2013.

Rossouw G.C., Smith J.P., Barril C. et al.: Carbohydrate distribution during berry ripening of potted grapevines: Impact of water availability and leaf-to-fruit ratio. - Sci. Hortic.Amsterdam 216: 215-225, 2017.

Roussos P.A., Sefferou V., Denaxa N.K. et al.: Apricot (Prunus armeniaca $\mathrm{L}$.) fruit quality attributes and phytochemicals under different crop load. - Sci. Hortic.-Amsterdam 129: 472-478, 2011.

Schreiber U., Billger W., Neubauer C.: Chlorophyll fluorescence as a non-destructive indicator for rapid assessment of in vivo photosynthesis. - In: Ernst-Detlef S., Caldwell M.M. (ed.): Ecophysiology of Photosynthesis. Pp. 49-70. Springer, Berlin - Heidelberg 1995.

Seehuber C., Damerow L., Blanke M.: Regulation of source: sink relationship, fruit set, fruit growth and fruit quality in European plum (Prunus domestica L.) - using thinning for crop load management. - Plant Growth Regul. 65: 335-341, 2011.

Syvertsen J.P., Goni C., Otero A.: Fruit load and canopy shading affect leaf characteristics and net gas exchange of 'Spring' navel orange trees. - Tree Physiol. 23: 899-906, 2003.

van Rooijen R., Aarts M.G., Harbinson J.: Natural genetic variation for acclimation of photosynthetic light use efficiency to growth irradiance in Arabidopsis. - Plant Physiol. 167: 1412-1429, 2015.

Zhen S.X., Shangguan Z.P.: Comparison of leaf gas exchange and chlorophyll fluorescence parameters in eight broad-leaved tree species. - Acta Ecol. Sin. 26: 1080-1087, 2006.

Zhu Z.J., Jiang C.Y., Shi Y.H. et al.: Response of yield and leaf photosynthesis to sink-source ratio altering demand in olive. Sci. Agri. Sinica 48: 546-554, 2015. 